\title{
Effects of Electromagnetic Fields on Osteogenesis of Human Alveolar Bone-Derived Mesenchymal Stem Cells
}

\author{
KiTaek Lim, ${ }^{1,2}$ Jin Hexiu, ${ }^{3}$ Jangho Kim, ${ }^{1}$ Hoon Seonwoo, ${ }^{1}$ Woo Jae Cho, ${ }^{1}$ \\ Pill-Hoon Choung, ${ }^{3,4}$ and Jong Hoon Chung ${ }^{1,5}$ \\ ${ }^{1}$ Department of Biosystems \& Biomaterials Science and Engineering, Seoul National University, \\ Seoul 151-921, Republic of Korea \\ ${ }^{2}$ Department of Oral and Maxillofacial Surgery and Dental Research Institute, School of Dentistry, \\ Seoul National University, Seoul 110-744, Republic of Korea \\ ${ }^{3}$ Department of Oral and Maxillofacial Surgery, Tooth Bioengineering National Research Lab, \\ School of Dentistry, Seoul National University, Seoul 110-744, Republic of Korea \\ ${ }^{4}$ Tooth Bioengineering National Research Laboratory of Post BK21, School of Dentistry, \\ Seoul National University, Seoul 110-744, Republic of Korea \\ ${ }^{5}$ Research Institute for Agriculture and Life Sciences, Seoul National University, Seoul 151-921, Republic of Korea
}

Correspondence should be addressed to Pill-Hoon Choung; choungph@snu.ac.kr and Jong Hoon Chung; jchung@snu.ac.kr

Received 3 April 2013; Accepted 1 May 2013

Academic Editor: Mouldy Sioud

Copyright (C) 2013 KiTaek Lim et al. This is an open access article distributed under the Creative Commons Attribution License, which permits unrestricted use, distribution, and reproduction in any medium, provided the original work is properly cited.

This study was performed to investigate the effects of extremely low frequency pulsed electromagnetic fields (ELF-PEMFs) on the proliferation and differentiation of human alveolar bone-derived mesenchymal stem cells (hABMSCs). Osteogenesis is a complex series of events involving the differentiation of mesenchymal stem cells to generate new bone. In this study, we examined not merely the effect of ELF-PEMFs on cell proliferation, alkaline phosphatase (ALP) activity, and mineralization of the extracellular matrix but vinculin, vimentin, and calmodulin (CaM) expressions in hABMSCs during osteogenic differentiation. Exposure of hABMSCs to ELF-PEMFs increased proliferation by $15 \%$ compared to untreated cells at day 5 . In addition, exposure to ELF-PEMFs significantly increased ALP expression during the early stages of osteogenesis and substantially enhanced mineralization near the midpoint of osteogenesis within 2 weeks. ELF-PEMFs also increased vinculin, vimentin, and CaM expressions, compared to control. In particular, CaM indicated that ELF-PEMFs significantly altered the expression of osteogenesis-related genes. The results indicated that ELF-PEMFs could enhance early cell proliferation in hABMSCs-mediated osteogenesis and accelerate the osteogenesis.

\section{Introduction}

We established an in vitro cell stimulation culture that was based on extremely low frequency pulsed electromagnetic fields (ELF-PEMFs) which were performed to find out the effects on the proliferation and differentiation of human alveolar bone-derived mesenchymal stem cells (hABMSCs). ELF-PEMFs stimulation may be clinically beneficial in the treatment of fracture healing, especially in nonunions [1$3]$. While there is a relatively frequent clinical use of electromagnetic stimulation, current evidence is insufficient to conclude a benefit of this treatment modality [4]. Aaron and Ciombor suggested that ELF-PEMFs-enhanced differentiation of mesenchymal stem cells is most likely responsible for the increase in extracellular matrix synthesis and bone maturation [5]. Recent studies indicated that progenitor cells might migrate into bone fracture sites and initiate osteogenic lineage commitment [6].

However, little is known about direct ELF-PEMFsinduced effects on osteoprogenitor cells as the most likely cell population contributing to the osteogenic response [6-9]. Only recently, Tsai et al. demonstrated a modulating role 
of ELF-PEMFs stimulation in MSC osteogenesis [8]. Furthermore, Sun et al. postulated that ELF-PEMFs exposure could enhance bone marrow mesenchymal stem cells proliferation [9]. To induce a biological response, translation of the electromagnetic signal into a biochemical signal is obligatory. Various, albeit somewhat conflicting, effects of ELF-PEMFs on transcriptional level and cell proliferation and differentiation have been reported in osteoblasts [1016]. Multiple studies report positive effects of ELF-PEMFs on mineralization in osteoblast-like cell cultures [17-19]. Besides, ELF-PEMFs-induced effects on cellular differentiation, there is increasing evidence suggesting that the effects of electromagnetic stimulation are also dependent on cellular maturation stage $[20,21]$.

Diniz et al. showed that ELF-PEMF had a stimulatory effect on the osteoblasts in the early stages of culture which increased bone tissue-like formation but decreased bone tissue-like formation in the mineralization stage. Although many factors are known to be involved in bone growth and repair, the transforming growth factor beta (TGF-b1) family of proteins, including bone morphogenetic proteins (BMPs), are of particular interest due to their well-recognized osteogenic potential [22-24].

Although the results have been somewhat controversial, a variety of cell responses have been observed involving proliferation and differentiation [25], gene expression [26], modulation of the membrane receptors functionality [27], apoptosis [28], alteration in ion homeostasis [28, 29], and free radicals generation [30-33]. We thought that ELF-PEMFs directly could stimulate osteoprogenitors towards osteogenic differentiation, and the paper showed the cell proliferation and osteogenic differentiation effects of ELF-PEMFs on hABMSCs. To date, there have been no studies investigating the effects of the pulsed electromagnetic field stimulation treatments on tooth tissue approaches.

Ultimately, the purpose of the research was to develop an optimized and appropriately characterized noninvasive treatment via ELF-PEMFs. Thus, the paper described preliminary findings regarding the effect of ELF-PEMFs exposure specifically on the proliferation and differentiation of hABMSCs.

\section{Materials and Methods}

2.1. Cell Culture. The cells were collected at the Intellectual Biointerface Engineering Center, Dental Research Institute, College of Dentistry, Seoul National University. Cells were cultured in $\alpha$-minimum essential medium (MEM) containing $10 \%$ fetal bovine serum (FBS, Welgene Inc., Republic of Korea), $10 \mathrm{mM}$ ascorbic acid (L-ascorbic acid), antibiotics, and sodium bicarbonate at $37^{\circ} \mathrm{C}$ in a humidified atmosphere of $5 \% \mathrm{CO}_{2}$ (Steri-Cycle 370 Incubator, Thermo Fisher Scientific. USA). The medium was changed every other day. hABMSCs were cultured after $24 \mathrm{~h}$ to facilitate attachment. When the cells became confluent, they were detached with $1 \mathrm{~mL}$ trypsin-EDTA, counted, and passaged. The cells were passaged before reaching confluence and used at between five and six passages.
2.2. Induction of Extremely Low Frequency Pulsed Electromagnetic Fields and Experimental Devices. The ELF-PEMFs stimulation system was developed for this study that ensures relatively uniform electromagnetic fields for cell culture. This apparatus included a waveform generator from 0 to $5 \mathrm{~V}$ and coils. The approximate average flux densities of the magnetic fields produced within the exposure apparatus of electromagnetic field was about $6 \mathrm{G} \pm 0.5$. The cells were continuously exposed to 10,30 , and $100 \mathrm{~Hz}$ ELF-PEMFs, respectively. The magnetic field sensor (CI-6520A, PASCO Ltd., CA, USA) is used in conjunction with a channel of the ScienceWorkshop 750 USB interface (CI-7599, PASCO Ltd., CA, USA) as shown in Figure 1. The magnetic flux density was monitored with a Gauss meter at the center of the top of each culture dishes, where hABMSCs attached themselves to the culture dishes. The culture dishes of the control group were placed next to those of experimental group in the same $\mathrm{CO}_{2}$ incubator. The flux density values of the culture dishes were no greater than $0.05 \mathrm{mT}$, the level of the natural magnetic field of the earth. The magnetic flux density was monitored via the PASCO's DataStudio software (CI-7599, PASCO Ltd, CA, USA) to collect and analyze data. Exposure was performed in the air gap of the iron core with the magnetic field verticality plane to the cell cultures. Exposure apparatus of ELF-PEMFs prepared for our study and $60 \mathrm{~mm}$ in diameter culture dish (Nunc, Denmark) were used. The electromagnetic field exposure system was put in an incubator at $37^{\circ} \mathrm{C}$; the culture dish was placed in the core of the solenoid where a homogeneous pulsed magnetic fields were generated (Figure 2), while control group was placed in a separate incubator.

2.3. Cell Proliferation and Viability Test. hABMSCs proliferation was measured by WST-1 assay (EZ-Cytox cell viability assay kit, Daeillab Service Co., LTD) as manufacture's protocols. The formazan dye produced by viable cells was quantified by a multiwell spectrophotometer (Victor 3, Perkin Elmer, USA), measuring the absorbance of the dye solution at $460 \mathrm{~nm}$. DNA concentration was quantified by fluorometry using the CyQUANT cell proliferation assay kit (Invitrogen) and the $\lambda$ DNA standard (Invitrogen) as manufacture's protocols. The CyQUANT is based on a strong increase in fluorescence of the CyQUANT GR dye when it binds cellular nucleic acids. Fluorescence was measured using a Cytofluor II fluorescence multiwell plate reader with excitation of $485 \mathrm{~nm}$ and emission of $530 \mathrm{~nm}$. Statistical significance was analyzed between the nontreatment and ELF-PEMFs groups. Values of ${ }^{*} P<0.05$ were considered to be statistically significant.

2.4. In Vitro Migration Study. hABMSCs were cultured with or without ELF-PEMFs, and cell morphology was observed by phase contrast microscopy (Nikon TS100, Japan). In vitro cell migration was assessed by CytoSelect Wound Healing Assay as manufacture's protocols. Wound closure was measured by microscopy for up to 72 hours, and photographs were taken. Cells were cultured with or without ELF-PEMFS, and cell morphology was periodically observed by phase contrast microscopy (Nikon TS100, Japan). hABMSCs were 


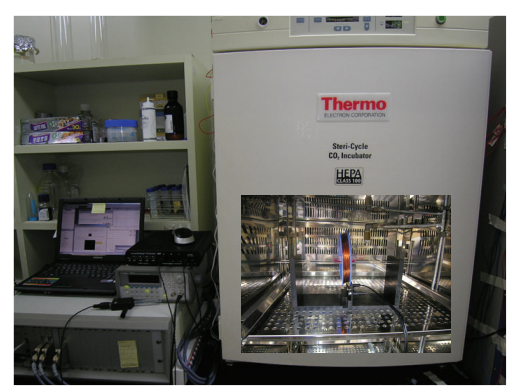

(a)

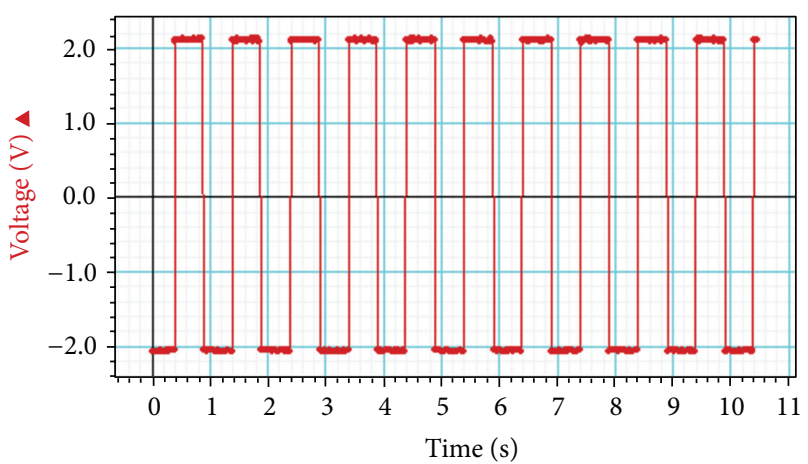

(d)

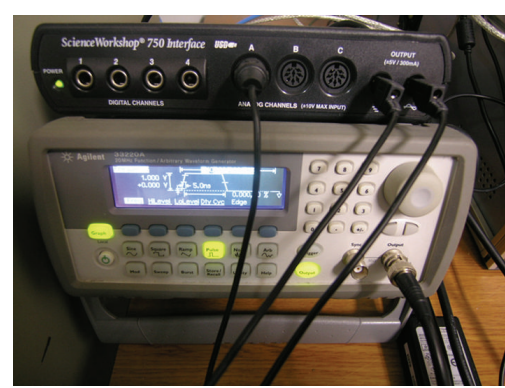

(b)

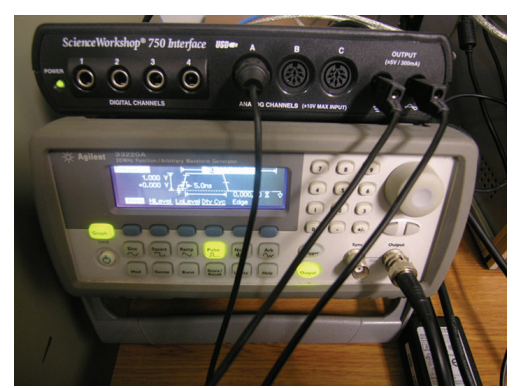

(c)

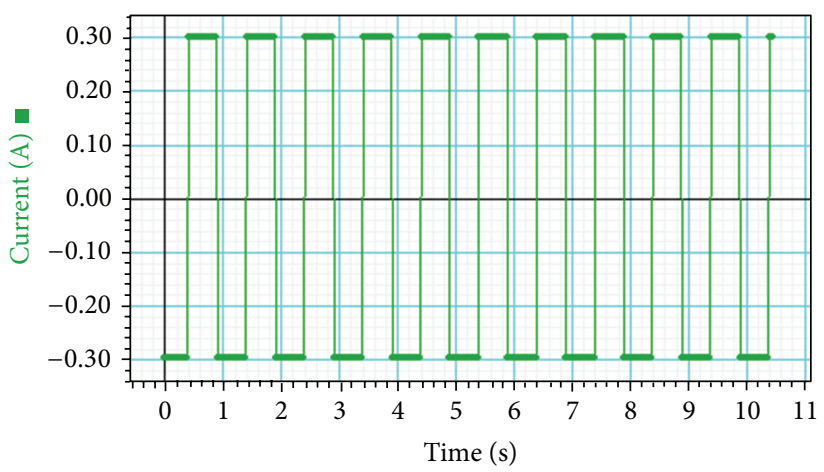

(e)

FIGURE 1: An extremely low frequency pulsed electromagnetic fields apparatus developed for this study; electromagnetic field apparatus system and $\mathrm{CO}_{2}$ incubator (a) the magnetic field sensor connected in conjunction with a channel of the ScienceWorkshop 750 USB interface (b). Electromagnetic field apparatus and the electromagnetic field exposure system put in an incubator in which the culture dish was placed in the core of the solenoid. The magnetic flux density was monitored via the PASCO's DataStudio software to collect and analyze data (c-e).

stimulated with exposure to ELF-PEMFs for 72 hours except for the control (without stimulation group).

2.5. Measurement of Alkaline Phosphatase Activity. Alkaline phosphatase (ALP) activity of the cell layer was quantified spectrophotometrically according to the instructions of the SensoLyteTM ALP Assay kit (AnaApec, USA). After centrifugation at $2500 \times \mathrm{g}$ for $10 \mathrm{~min}$ at $4^{\circ} \mathrm{C}$, enzyme activity was calculated by measuring the yellow $\mathrm{p}$-nitrophenol product formed at $405 \mathrm{~nm}$ (Victor 3, Perkin Elmer, USA).

2.6. Measurement of Mineralized Nodule Formation. hABMSCs were placed in $35 \mathrm{~mm}$ culture dishes at a density of $1.0 \times 10^{4}$ cells $/ \mathrm{cm}^{2}$ and cultured for about 2 weeks in $\alpha$ MEM containing $50 \mathrm{mM} \beta$-glycerophosphate and $50 \mu \mathrm{g} / \mathrm{mL}$ ascorbic acid, with and without ELF-PEMFs. The induction culture medium was changed every second or third day. The cells were exposed to ELF-PEMFs for 2 weeks (10 min duration/day) except for control (without stimulation group). Condition and nodule formation were checked routinely by phase contrast microscopy. The presence of mineralized nodules (calcium deposition) was determined by staining with alizarin red, as described [34]. The ethanol-fixed cells and matrix were stained for $1 \mathrm{~h}$ with $40 \mathrm{mM}$ alizarin red-S $(\mathrm{pH}$ 4.2) and extensively rinsed with water. After photography, the bound stain was eluted with $10 \%$ (wt/vol) cetylpyridinium chloride, and alizarin red-S in samples was quantified by measuring absorbance at $544 \mathrm{~nm}$ (Victor 3, Perkin Elmer, USA). Vitamin C, $\beta$-glycerophosphate, alizarin red-S, and cetylpyridinium chloride were obtained from Sigma-Aldrich (St. Louis, MO, USA).

2.7. Fluorescence Microscopy Analysis. The cells were washed in phosphate buffered saline (PBS, Sigma-Aldrich, Milwaukee, WI, USA), fixed in a $4 \%$ paraformaldehyde solution (Sigma-Aldrich, Milwaukee, WI, USA) for $20 \mathrm{~min}$, and permeabilized with $0.2 \%$ Triton X-100 (Sigma-Aldrich, WI, Milwaukee, USA) for $15 \mathrm{~min}$. Cells were incubated with TRITC-conjugated phalloidin, anti-vinculin, its secondary antibody (Millipore Cat. no. AP124F), and 4, 6-diamidino-2phrnykinodole (DAPI; Millipore, Billerica, MA, USA) for $1 \mathrm{~h}$ to stain actin filaments, focal contracts, and nuclei, respectively. Cytoskeleton organization was visualized using an actin cytoskeleton and focal adhesion staining kit (FAK100; Millipore, Billerica, MA) according to the manufacturer's instruction. In addition, stem cell surface markers of mesenchymal stem cells were captured using STRO-1 (Santa Cruz Biotechnology, USA) and CD146 (BD bioscience, USA) according to the manufacturer's instruction. Cells were mounted in glycerol/buffer on a glass slide after extensive washing with PBS. Images of labeled cells were obtained by a fluorescence image restoration microscope (Applied Precision, USA). 


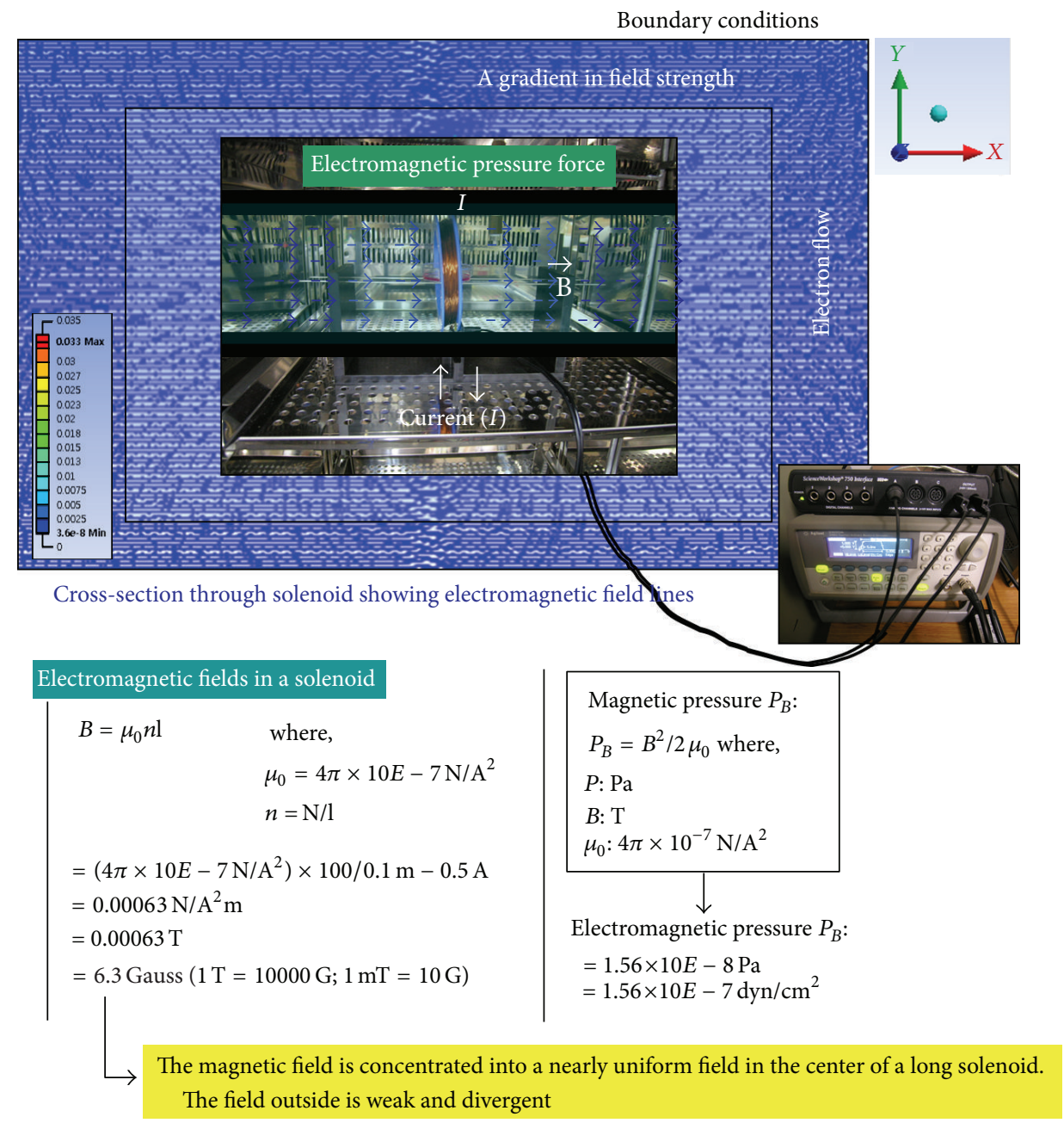

(a)
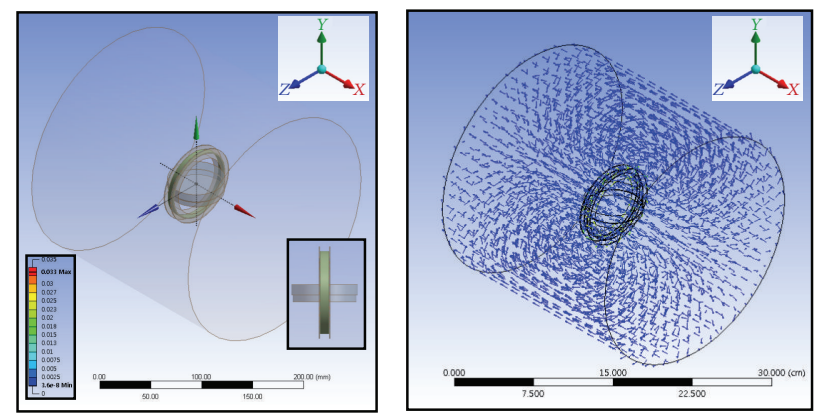

(b)
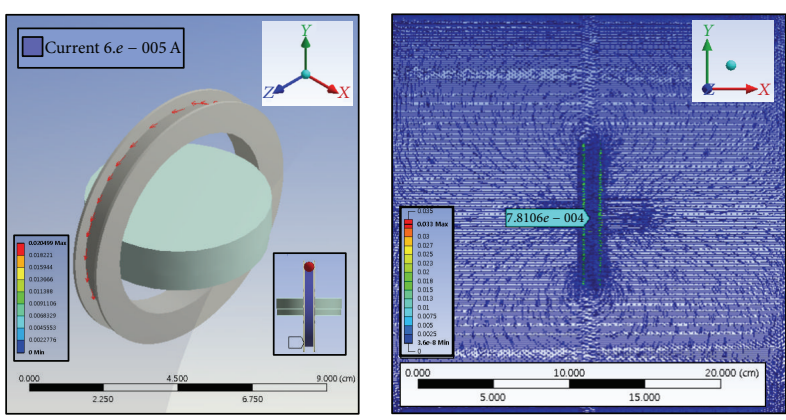

(c)

FIGURE 2: Electromagnetic fields and modeling by CFD. The electromagnetic pressure force is an energy density associated with the magnetic field strength by electric fields. We calculated electromagnetic fields values (a) in a solenoid which was concentrated into nearly uniform fields (b) in the center of a long solenoid (c).

2.8. Confocal Microscopy and Immunohistochemistry. Cells were washed in phosphate buffered saline (PBS, SigmaAldrich, Milwaukee, WI, USA), fixed in a $4 \%$ paraformaldehyde solution (Sigma-Aldrich, Milwaukee, WI, USA) for
20 min, and permeabilized with $0.2 \%$ Triton X-100 (SigmaAldrich, WI, Milwaukee, USA) for $15 \mathrm{~min}$. Cells were incubated with TRITC-conjugated Phalloidin, anti-osteocalcin, its secondary antibody (Cat. no. AB10911, millipore), and 

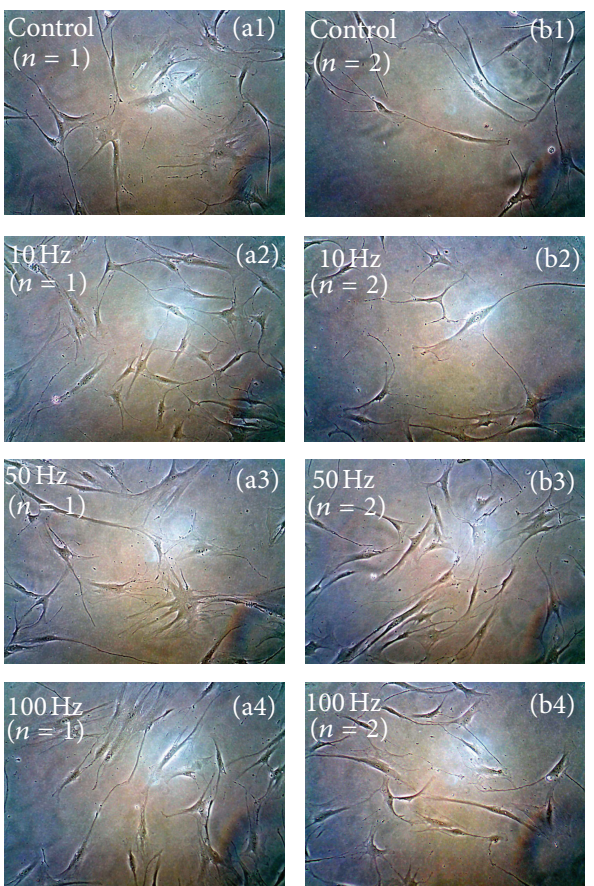

(a)

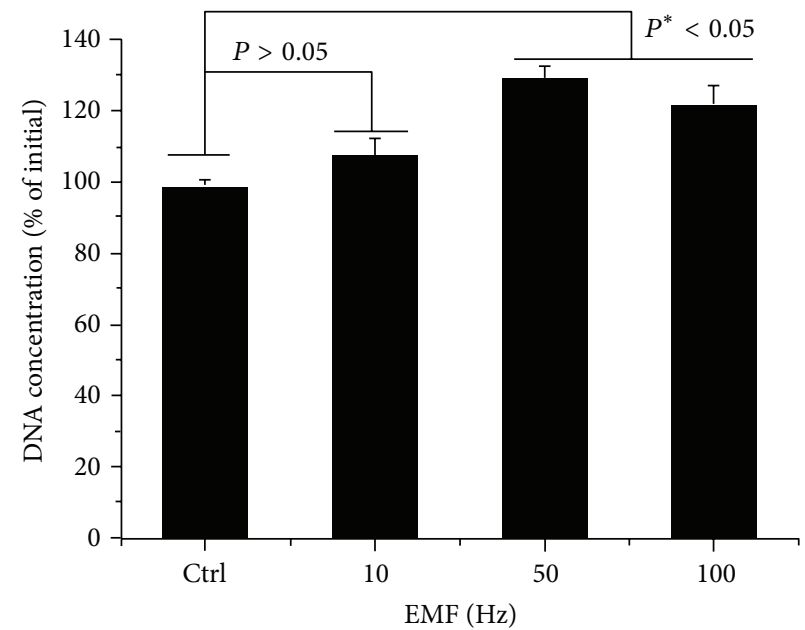

(c)
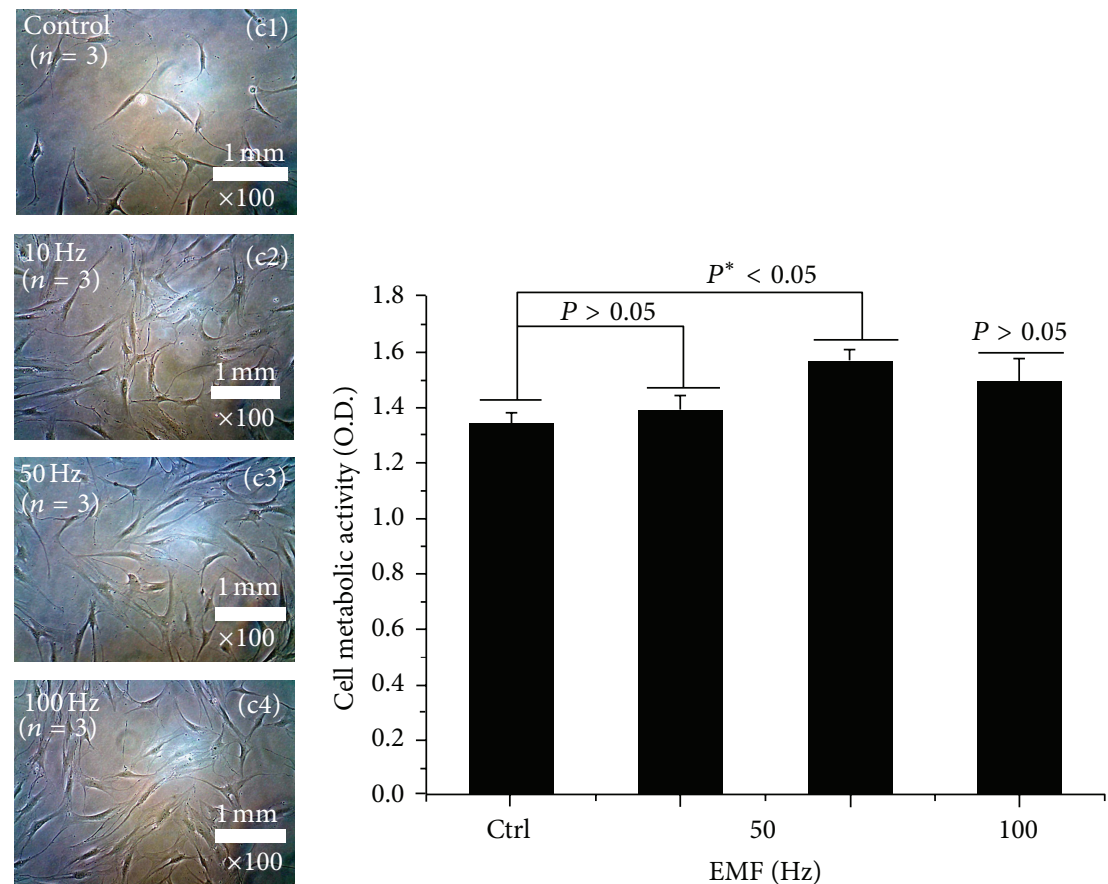

(b)

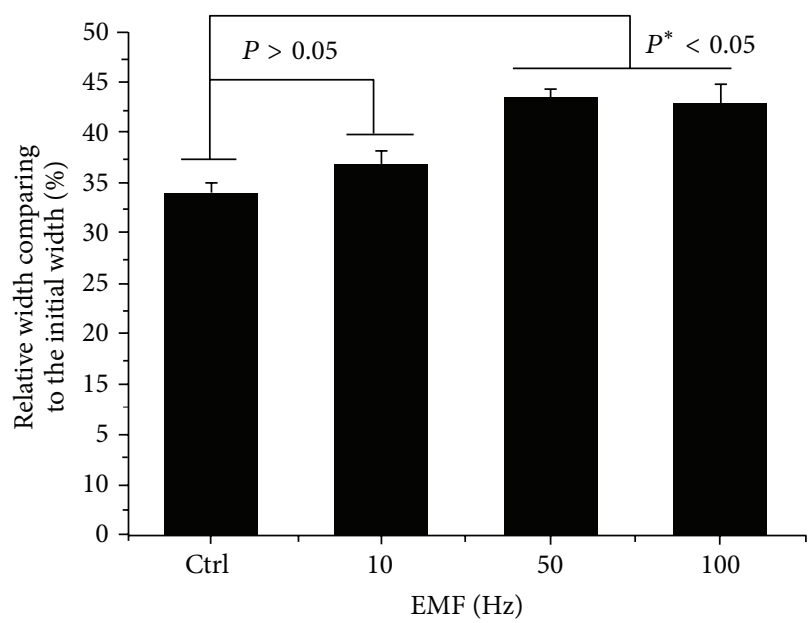

(d)

Figure 3: Representative optical microscopic images $(a, n=3)$ of hABMSCs exposed for 4 days in static condition (al-c1) or ELF-PEMFs (intensity, 6 Gauss) induction at $10 \mathrm{~Hz} /$ day (a2-c2), $50 \mathrm{~Hz} /$ day (a3-c3), and $100 \mathrm{~Hz} /$ day. Cell metabolic viabilities as optical density (O.D.) of hABMSCs measured using WST-1 (b). DNA concentration (c) as a percent of initial of hABMSCs measured using CyQUANT cell proliferation assay kit $(n=3)$. In vitro cell migration indicating that ELF-PEMFs (intensity, 6 Gauss) group exposed at 10, 50 , and $100 \mathrm{~Hz}$ in $6 \mathrm{G}$. Fifty and $100 \mathrm{~Hz}$ were statistically significant differences $\left({ }^{*} P<0.05\right)$ among groups $(\mathrm{d})(n=3)$. Overhead brackets with asterisks indicate statistically significant differences between groups.

4, 6-diamidino-2-phrnykinodole (DAPI; Millipore, Billerica, MA, USA) for $1 \mathrm{~h}$ to stain actin filaments, focal contracts, and nuclei, respectively. In addition, the major intermediate filament protein of mesenchymal stem cells was visualized using an anti-Connexins 43 (Cat. no. AB1728, Millpore) according to the manufacturer's instruction. Connexin 43 is a member of the connexin gene family and a component of gap junctions. Gap junctions are composed of arrays of intercellular channels and provide a route for the diffusion of materials of low molecular weight from cell to cell. Negative controls were used during immunostaining by omitting primary antibodies, and at least two independent stainings were performed. Cells were mounted in glycerol/buffer on a glass slide after extensive washing with PBS. Images of labeled 


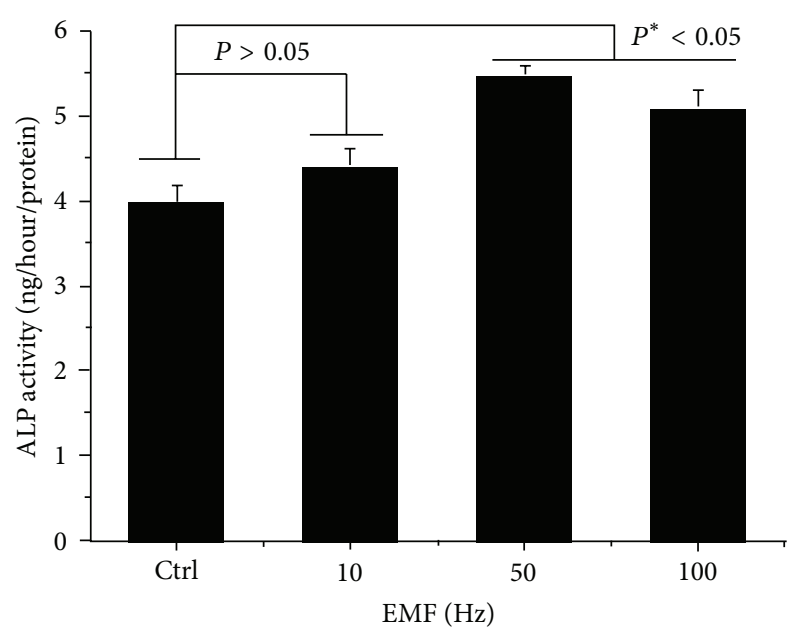

FIGURE 4: ALP activity cultured in different types of hABMSCs exposed with ELF-PEMFs (intensity, 6 Gauss) for 7 days. ELFPEMFs induction group exposed at $50 \mathrm{mT} /$ day and $100 \mathrm{mT} /$ day $\left({ }^{*} P<0.05\right)$ have statistically significant differences among groups $(n=3)$.

cells were obtained by a confocal laser scanning microscope (Carl Zeiss, LSM710).

2.9. Statistical Analysis. Statistical analysis was carried out using the statistical analysis system (SAS) for Windows v8.2 (SAS Institute, Inc., Cary, NC, USA). Statistical significance between control and treatment groups was compared with two-way ANOVA and Duncan's multiple range tests at $P<$ 0.05 . The data were reported as the mean \pm standard deviation.

\section{Results and Discussion}

3.1. Cell Morphology, Cell Viability, and Proliferation Enhanced by ELF-PEMFs Induction. Cell morphologies were shown in representative optical microscopic images (Figure 3(a), $n=$ 3) of hABMSCs stimulated by ELF-PEMFs induction for 4 days in one of the following exposure conditions: static condition (al-c1) or ELF-PEMFs (intensity, 6 Gauss) induction at $10 \mathrm{~Hz} /$ day (a2-c2), $50 \mathrm{~Hz} /$ day (a3-c3), and $100 \mathrm{~Hz} /$ day. Cells showed that ELF-PEMFs induction-stimulated groups had greater cell numbers and cell growth than the static group. Cell metabolic viabilities were measured as optical densities of hABMSCs using WST-1 (Figure 3(b)). DNA concentration (Figure 3(c)) as the percent of initial of hABMSCs measured using CyQUANT cell proliferation assay kit $(n=3)$. In vitro cell migration as representative optical microscopic images with ELF-PEMFs induction groups compared to static culture (Figure 3(d)), indicating that ELF-PEMFs (intensity, 6 Gauss) group exposed at 10,50 , and $100 \mathrm{~Hz}$ in $6 \mathrm{G}$. Fifty and $100 \mathrm{~Hz}$ were statistically significant differences $\left({ }^{*} P<0.05\right)$ among groups $(\mathrm{d})(n=3)$. Overhead brackets with asterisks indicate statistically significant differences between groups. The growth of hABMSCs was significantly increased at the ELF-PEMFs intensity levels, indicating that they are the optimal conditions. ELF-PEMFs have previously been associated with increased collagen deposition, enhanced ion transport and amino acid uptake, fibroblast migration, and ATP and protein synthesis. ELF-PEMFs may have an effect on intracellular ion control, especially $\mathrm{Ca}^{2+}$, as well as on mRNA expression, protein synthesis, and gene expression [35]. Consequently, we observed that lower ELF-PEMFs intensities (intensity, 6 Gauss) and wavelength (optimal frequency) induced greater cell metabolic activity. The hABMSCs proliferated and expanded significantly better under ELF-PEMFs of 50 and $100 \mathrm{~Hz}$ groups than in the control.

3.2. Synergistic Effects of Osteogenic Differentiation by ELFPEMFs Induction. ALP activity was maintained during the 7 days of culture (Figure 4). ELF-PEMFs groups exposed at 50 and $100 \mathrm{~Hz} /$ day $\left({ }^{*} P<0.05\right)$ had statistically significant group differences. The early osteoblastic marker was also expressed over the range of ELF-PEMFs. We also investigated the effects of long-term ELF-PEMFs on the differentiation of hABMSCs. We observed that the formation of mineralized nodules is one of the markers of osteoblastic maturation. Figure 5(a) showed representative optical microscopic images of hABMSCs after alizarin red staining treatment with static condition (al, a2) or ELF-PEMFs (intensity, 6 Gauss) at $10 \mathrm{~Hz} /$ day (b1, b2), $50 \mathrm{~Hz} /$ day (c1, c2), and $100 \mathrm{~Hz} /$ day (d1, d2) at 1 and 2 weeks, respectively. ELF-PEMFs induction groups at 50 and $100 \mathrm{~Hz} /$ day were way too much intense compared to control (Figure 5(b), white arrows: mineral nodules stained in red). Mineralized nodule as optical density (absorbance of $562 \mathrm{~nm}$ ) measured after destaining treatment Figure 5(c). ELF-PEMFs induction exposed at 50 and $100 \mathrm{~Hz} /$ day groups was statistically significant differences $\left({ }^{*} P<0.05\right)$ among groups. $(n=3$, bar $=1 \mathrm{~mm})$. The hABMSCs cultured with ELFPEMFs under conditioned media showed increased calcium contents, whereas the cells cultured under normal growth media showed no or a low increase of calcium, despite ELFPEMF treatment (Figure 5(b): a3-d3). Figure 5(c) showed the optical density value of mineralized nodules (absorbance of $562 \mathrm{~nm}$ ) measured after destaining treatment. ELF-PEMFs induction groups had statistically significant differences $\left({ }^{*} P<0.05,50\right.$ and $100 \mathrm{~Hz} /$ day; $n=3$, bar $\left.=1 \mathrm{~mm}\right)$. These results showed that optimal ELF-PEMFs induction with the proper intensity and frequency condition could enhance the differentiation and maturation of hABMSCs synergistically.

\subsection{Increased Expression of CaM via ELF-PEMFs. Figure 6} showed representative confocal laser microscopy images of hABMSCs cultured for 7 days in static conditions (al-d1) or ELF-PEMFs induction (intensity, 6 Gauss) at $10 \mathrm{~Hz} /$ day (a2-d2), $50 \mathrm{~Hz} /$ day (a3-d3), and $100 \mathrm{~Hz} /$ day (a4-d4) groups; cell nuclei (al-d4), actin filaments (b1-b4), vimentin (cl$\mathrm{c} 4)$, and merged images (d1-d4) of the fluorescence stains. Confocal laser microscopy images showed more intense observation at ELF-PEMFs induction groups compared to control group (arrows: cell direction). The role of calcium ions $\left(\mathrm{Ca}^{2+}\right)$ in cell function is beginning to be unraveled 

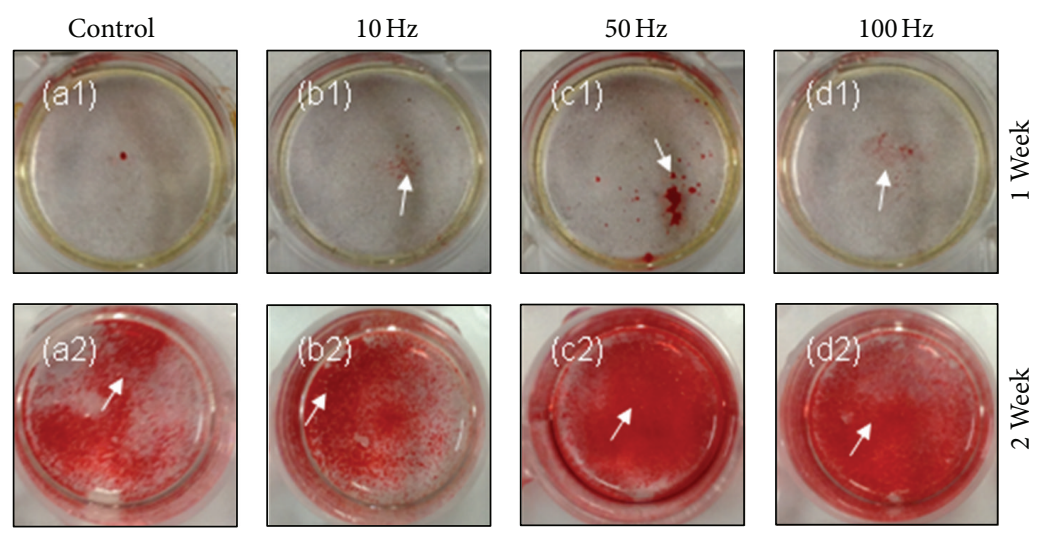

(a)
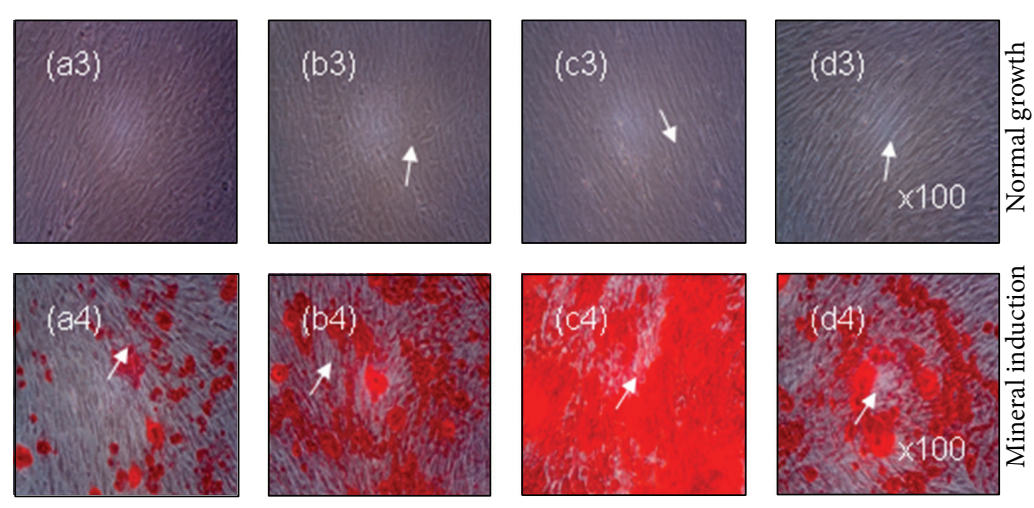

(b)

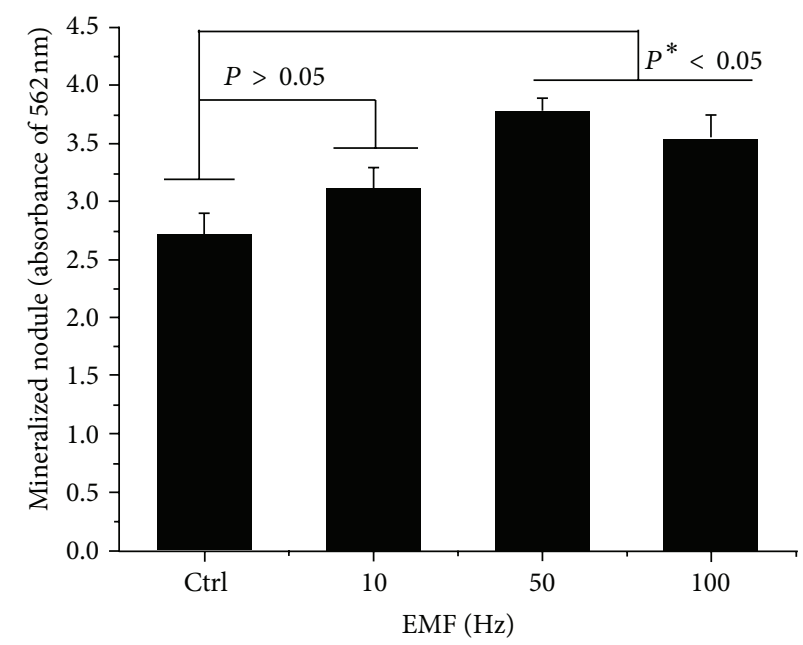

(c)

FIGURE 5: Representative optical microscopic images of hABMSCs after alizarin red staining treatment with static condition (a1, a2) or ELFPEMFs (intensity, 6 Gauss) at $10 \mathrm{~Hz} / \mathrm{day}(\mathrm{b} 1, \mathrm{~b} 2), 50 \mathrm{~Hz} / \mathrm{day}(\mathrm{cl}, \mathrm{c2})$, and $100 \mathrm{~Hz} / \mathrm{day}(\mathrm{d} 1, \mathrm{~d} 2)$ at 1 and 2 weeks, respectively. ELF-PEMFs induction groups at 50 and $100 \mathrm{~Hz} /$ day were way too much intense compared to control (b, white arrows: mineral nodules stained in red). Mineralized nodule as optical density (absorbance of $562 \mathrm{~nm}$ ) measured after destaining treatment (c). ELF-PEMFs induction exposed at 50 and $100 \mathrm{~Hz} /$ day groups have statistically significant differences $\left({ }^{*} P<0.05\right)$ among groups $(n=3$, bar $=1 \mathrm{~mm})$.

at the molecular level as a result of recent research on calcium-binding proteins and particularly on CaM. Calcium, in conjunction with the calcium-binding protein $\mathrm{CaM}$, is a key mediator in signal transduction [36].
For external stimuli such as ELF-PEMFs to affect the behavior of proliferation and differentiation of hABMSCs, signal transduction must occur across the cell membrane. There are two approaches to signal transduction: activation 

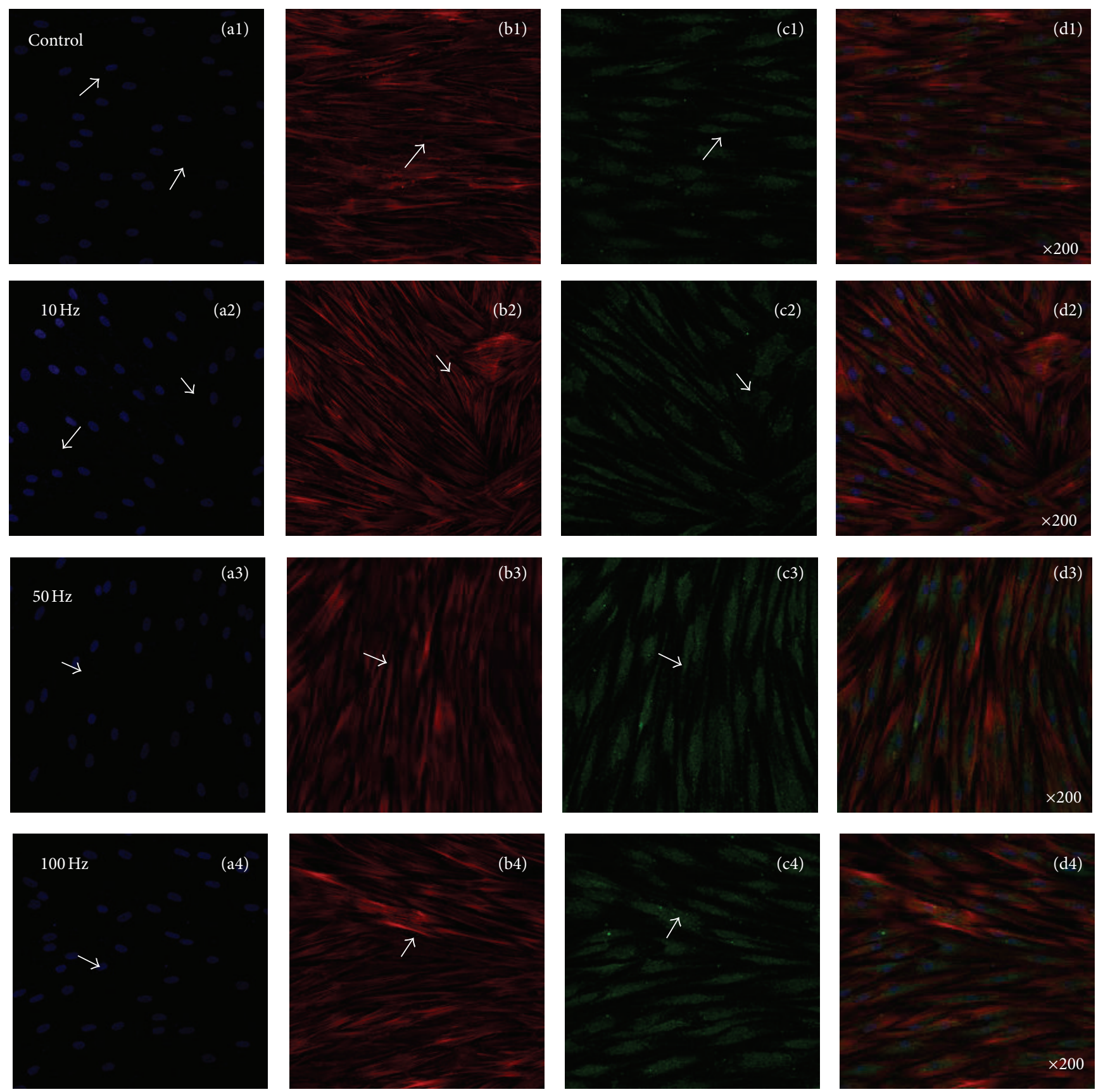

Figure 6: Representative confocal laser microscopy images of hABMSCs cultured for 7 days in static conditions (a1-d1) or ELF-PEMFs induction (intensity, 6 Gauss) at $10 \mathrm{~Hz} /$ day (a2-d2), $50 \mathrm{~Hz} /$ day (a3-d3), and $100 \mathrm{~Hz} /$ day (a4-d4) groups; cell nuclei (al-d4), actin filaments (b1-b4), calmodulin (CaM, c1-c4), and merged images (d1-d4) of the fluorescence stains. Confocal laser microscopy images showed more intense observation at ELF-PEMFs induction groups compared to control group (arrows: cell direction).

of transmembrane channels or alteration of transmembrane receptors. Preliminary observations made by Aaron et al. suggested that the cellular response to ELF-PEMFs exposure might involve the calcium/CaM pathway [37]. However, inconsistent results regarding transmembrane channel activation still exist among researchers. On the other hand, the effectiveness of ELF-PEMFs may depend on a series of amplification mechanisms that occur during transmembrane coupling. The likely sites of amplification are the transmembrane receptors. Studies have shown that ELF-PEMFs alter membrane functions such as ion channels, ligand binding, and alterations in the density and distribution of receptors 

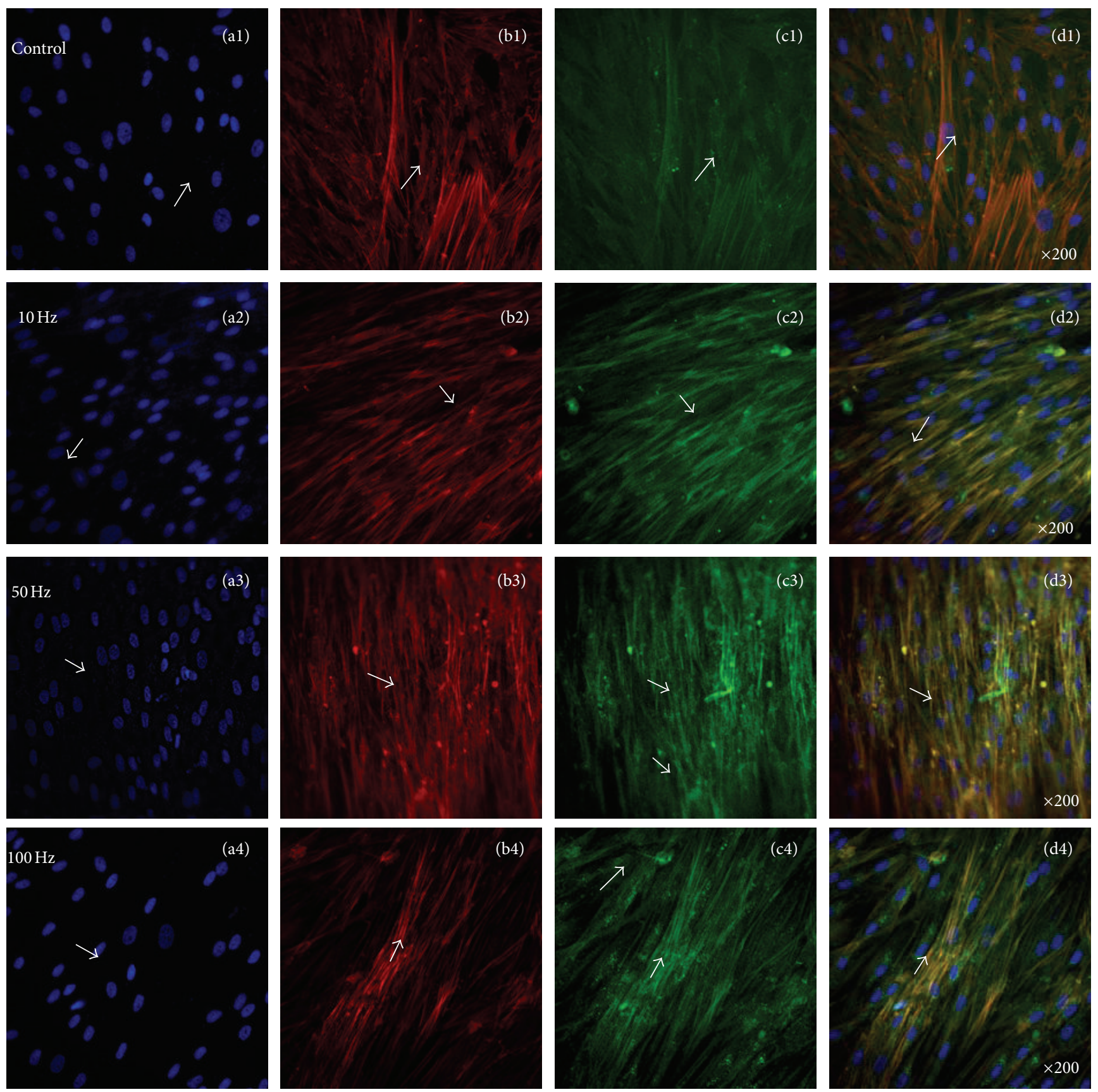

Figure 7: Representative confocal laser microscopy images of hABMSCs cultured for 7 days in static conditions (al-d1) or ELF-PEMFs induction (intensity, 6 Gauss) at $10 \mathrm{~Hz} /$ day (a2-d2), $50 \mathrm{~Hz} /$ day (a3-d3), and $100 \mathrm{~Hz} /$ day (a4-d4) groups; cell nuclei (a1-d4), actin filaments (b1-b4), vinculin (cl-c4), and merged images (d1-d4) of the fluorescence stains. Confocal laser microscopy images showed more intense observation at ELF-PEMFs induction groups compared to control group (arrows: cell direction).

[38-40]. Each of these mechanisms has the ability to affect transmembrane signaling. As reported, hABMSCs growth was a significant difference $\left({ }^{*} P<0.05\right)$ with respect to the control. These findings indicated that ELF-PEMFs for hABMSCs had the ability to enhance cell proliferation and differentiation as one of the noninvasive stimulation methods.
3.4. Enhanced Adhesion of Vinculin and Vimentin via ELF-PEMFs. Figure 7 showed representative confocal laser microscopy images of hABMSCs cultured for 7 days in static conditions (a1-d1) or ELF-PEMFs induction (intensity, 6 Gauss) at $10 \mathrm{~Hz} /$ day (a2-d2), $50 \mathrm{~Hz} /$ day (a3-d3), and $100 \mathrm{~Hz} /$ day (a4-d4) groups; cell nuclei (a1-d4), actin filaments (b1-b4), vinculin (c1-c4), and merged images (d1-d4) 

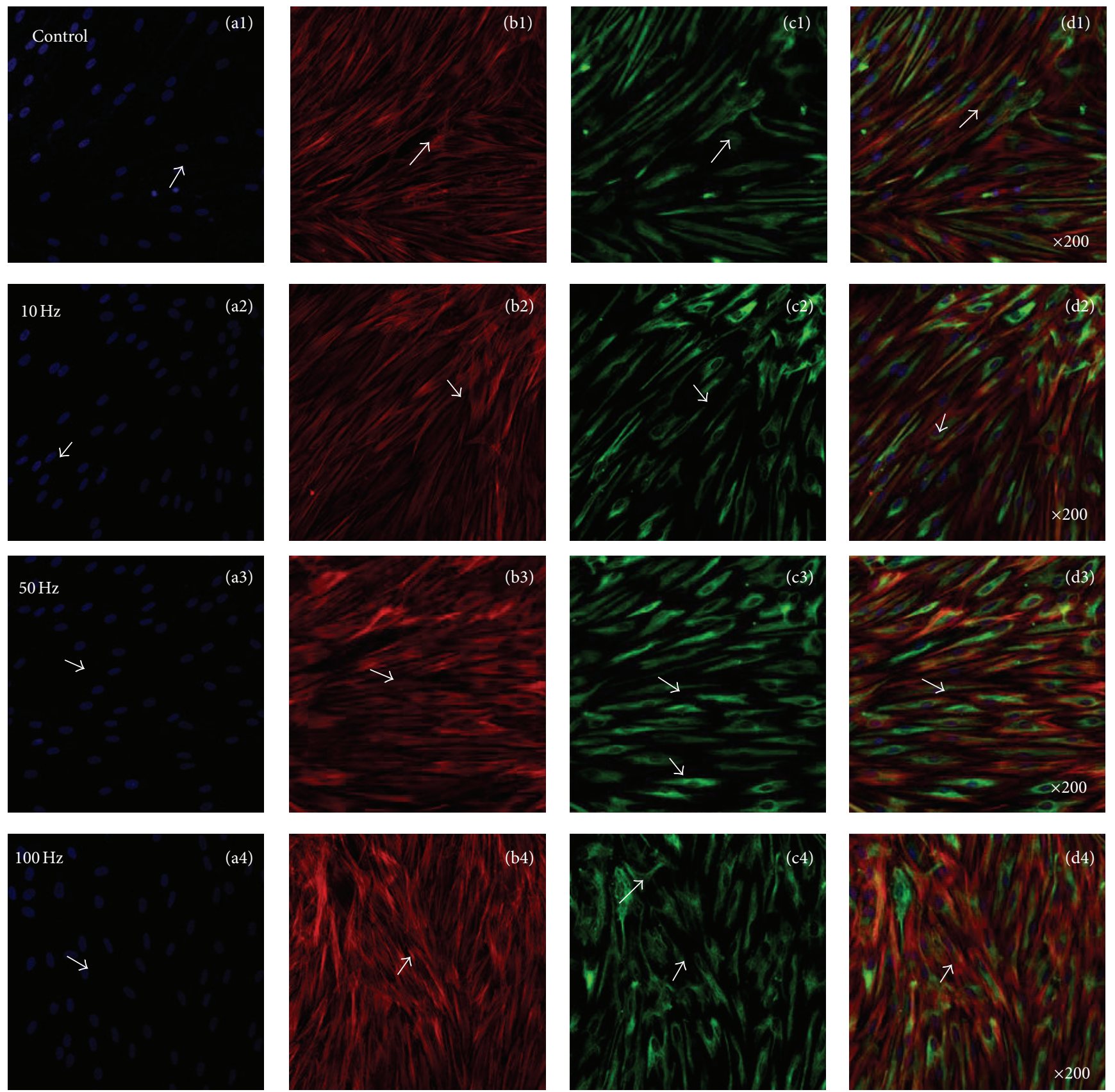

FIGURE 8: Representative confocal laser microscopy images of hABMSCs cultured for 7 days in static conditions (al-d1) or ELF-PEMFs induction (intensity, 6 Gauss) at $10 \mathrm{~Hz} /$ day (a2-d2), $50 \mathrm{~Hz} /$ day (a3-d3), and $100 \mathrm{~Hz} /$ day (a4-d4) groups; cell nuclei (a1-d4), actin filaments (b1-b4), vimentin (cl-c4), and merged images ( $\mathrm{d} 1-\mathrm{d} 4)$ of the fluorescence stains. Confocal laser microscopy images showed more intense observation at ELF-PEMFs induction groups compared to control group (arrows: cell direction).

of the fluorescence stains. Confocal laser microscopy images showed more intense observation at ELF-PEMFs induction groups compared to control group (arrows: cell direction). Figure 8 showed representative confocal laser microscopy images of hABMSCs cultured for 7 days in static conditions (a1-d1) or ELF-PEMFs induction (intensity, 6 Gauss) at $10 \mathrm{~Hz} /$ day (a2-d2), $50 \mathrm{~Hz} /$ day (a3-d3), and $100 \mathrm{~Hz} /$ day (a4d4) groups; cell nuclei (al-d4), actin filaments (b1-b4), vimentin (c1-c4), and merged images (d1-d4) of the fluorescence stains. Confocal laser microscopy images showed 

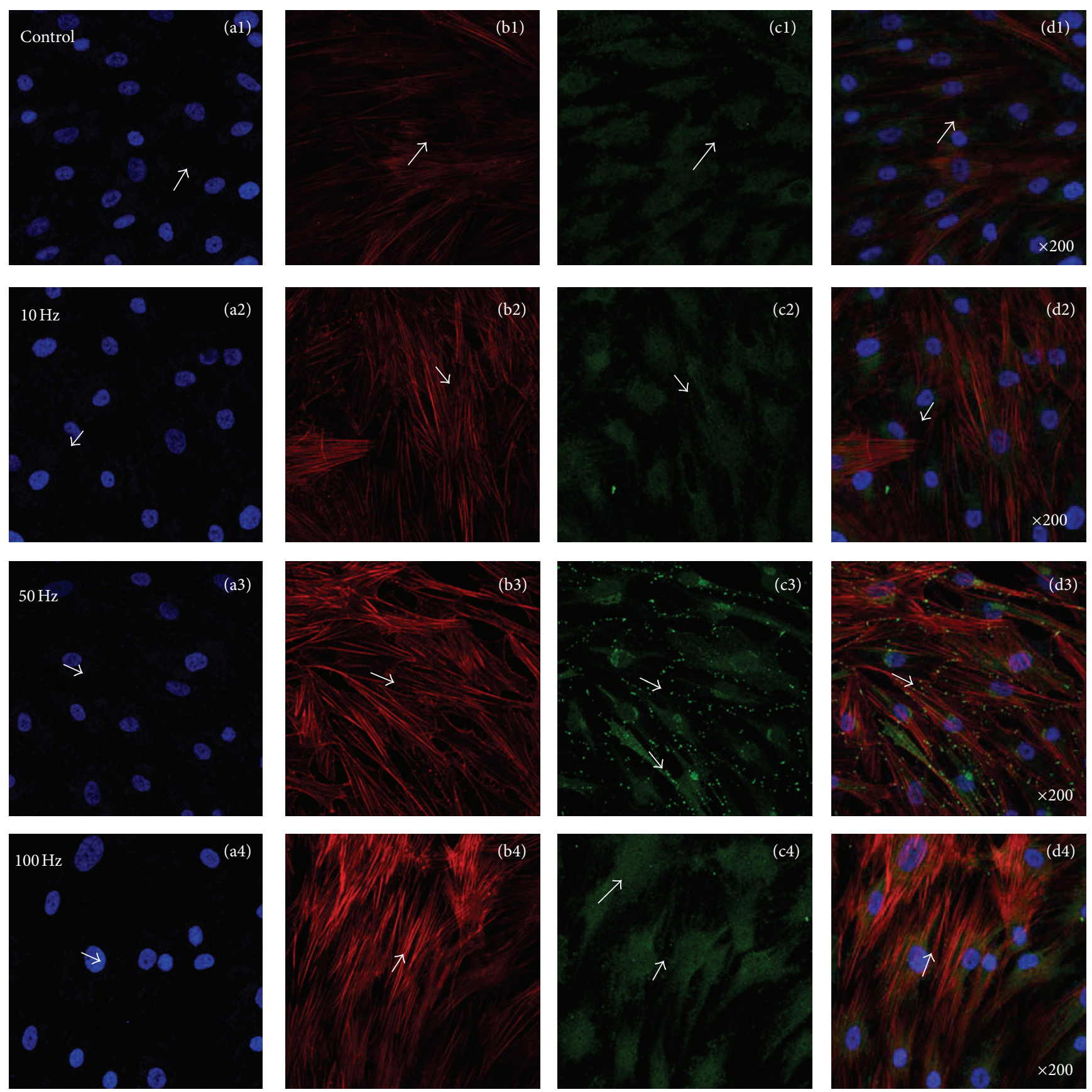

Figure 9: Representative confocal laser microscopy images of hABMSCs cultured for 7 days in static conditions (a1-d1) or ELF-PEMFs induction (intensity, 6 Gauss) at $10 \mathrm{~Hz} /$ day (a2-d2), $50 \mathrm{~Hz} /$ day (a3-d3), and $100 \mathrm{~Hz} /$ day (a4-d4) groups; cell nuclei (a1-d4), actin filaments (b1-b4), osteocalcin (OCN, cl-c4), and merged images (d1-d4) of the fluorescence stains. Confocal laser microscopy images showed more intense observation at ELF-PEMFs induction groups compared to control group (arrows: cell direction). 
more intense observation at ELF-PEMFs induction groups compared to control group (arrows: cell direction). Recent studies have revealed that also vimentin has key roles in adhesion by regulating integrin functions. Among the large protein family of intermediate filaments, vimentin is one of the most familiar members, as it is the major intermediate filaments (IFs) protein in mesenchymal cells, and it is frequently used as a developmental marker of cells and tissues. It is well established that IFs have an important role in adhesion and cell-cell interactions through their association with hemidesmosomes and desmosomes [41]. Recent studies have revealed that also vimentin has key roles in adhesion by regulating integrin functions.

3.5. Enhanced Osteoinduction of Osteocalcin via ELF-PEMFs. Figure 9 showed representative confocal laser microscopy images of hABMSCs cultured for 7 days in static conditions (a1-d1) or ELF-PEMFs induction (intensity, 6 Gauss) at $10 \mathrm{~Hz} /$ day (a2-d2), $50 \mathrm{~Hz} /$ day (a3-d3), and $100 \mathrm{~Hz} /$ day (a4d4) groups; cell nuclei (al-d4), actin filaments (b1-b4), osteocalcin (OCN, cl-c4), and merged images (d1-d4) of the fluorescence stains. Confocal laser microscopy images showed more intense observation at ELF-PEMFs induction groups compared to control group (arrows: cell direction). The CaM could promote the proliferation and differentiation of $\mathrm{hABM}$ SCs via the effect of altered $\mathrm{Ca}^{2+}$ concentrations which could provide evidence for CaM signaling in cellular migration, proliferation, and differentiation. Thus, signal transduction via ELF-PEMFs ultimately could affect enhanced adhesion molecules and then finally promote enhanced osteogenesis. The results suggest that ELF-PEMFs at the proper intensity enhance the differentiation and maturation of hABMSCs.

The influence of ELF-PEMFs on cell proliferation in the $\mathrm{mT}$ range of magnetic flux density has been investigated by many authors. Khalil and Qassem [42] noted a decrease in proliferation index after exposure of lymphocytes to a $1 \mathrm{mT}$ $50 \mathrm{~Hz}$ field. A single exposure for $60 \mathrm{~min}$ to a $2 \mathrm{mT} 50 \mathrm{~Hz}$ magnetic field led to a decrease in cell number of about $-10 \%$ of control SV40-3T3 monolayers $6 \mathrm{~h}$ subsequent to the exposure [43]. These biological factors are known to be strong modifiers of the cellular response towards the fields [44-46]. The cell membrane has high impedance [47]. As a result, electric fields can polarize membrane components, move receptors or channels by electrophoresis within the membrane, or alter receptor conformation [48]. A past study has shown that DC electric fields can affect the assembly and distribution of actin filaments within the cytoplasm of endothelial cells $[49,50]$.

According to the electrochemical information transfer hypothesis, low level electromagnetic and permanent magnetic fields interact with cell membranes by enhancing the binding rate of ions with enzymes and receptors [51-53]. Ions such as calcium play an important role in regulating cell shape. Calcium is responsible for regulating changes in the actin filament meshwork that is present in the cytoplasm of chondrocytes [54]. According to the present mechanism, there is also an explanation why pulsed electromagnetic fields can be more bioactive than continuous fields of the same characteristics, or why the greatest effects of a continuous field may occur with onset or removal of exposure to this. Such phenomena have been observed in several experiments [55-57] and until now there was not any theoretical explanation.

Finally, our results that ELF-PEMFs induction is quite efficient for improving the proliferation and differentiation of hABMSCs suggest that it may be a good strategy for hABMSCs-based tissue engineering applications with suitable scaffolds, especially fabricated by conducting biomaterials [58-61].

\section{Conclusions}

This study was performed to investigate the effects of ELFPEMFs induction on the proliferation and differentiation of hABMSCs. We studied cell proliferation, migration, mineralized nodule formation, von Kossa, and ALP activity as indicators of osteogenesis. The results indicated that ELFPEMFs induction created an important synergistic effect for activating mechanotransduction. We found synergistic effects of ELF-PEMFs on the proliferation and differentiation of hABMSCs. Alizarin red staining showed that mineralized nodules formed intensely (intensity, 6 Gauss, frequency, 50 and $100 \mathrm{~Hz}$ ). ALP activity in similar intensity groups had statistically significant group differences. We also examined vinculin, vimentin, and CaM expressions during osteogenic differentiation. ELF-PEMFs increased vinculin, vimentin, and CaM expressions, compared to control. In particular, CaM indicated that ELF-PEMFs significantly altered expression of osteogenesis-related genes. The results showed that ELF-PEMFs could enhance cell proliferation and accelerate the osteogenesis. In conclusion, the present findings could suggest that ELF-PEMFs at the proper intensity enhanced bone formation by promoting the differentiation and maturation of the stem cells.

\section{Conflict of Interests}

The authors declare that they have no conflict of interests.

\section{Acknowledgment}

This research was supported by Technology Development Program for IPET (Korea Institute of Planning and Evaluation for Technology in Food, Agriculture, Forestry and Fisheries), Republic of Korea (312031-3).

\section{References}

[1] R. K. Aaron, D. M. Ciombor, and B. J. Simon, "Treatment of nonunions with electric and electromagnetic fields," Clinical Orthopaedics and Related Research, no. 419, pp. 21-29, 2004.

[2] K. T. Lim, J. H. Kim, H. Seonwoo et al., "In vitro effects of electromagnetic field stimulation on cells in tissue engineering," Tissue Engineering and Regenerative Medicine, vol. 6, no. 4, pp. 675-684, 2009. 
[3] X. L. Griffin, F. Warner, and M. Costa, "The role of electromagnetic stimulation in the management of established non-union of long bone fractures: what is the evidence?" Injury, vol. 39, no. 4, pp. 419-429, 2008.

[4] B. Mollon, V. Da Silva, J. W. Busse, T. A. Einhorn, and M. Bhandari, "Electrical stimulation for long-bone fracture-healing: a meta-analysis of randomized controlled trials," Journal of Bone and Joint Surgery A, vol. 90, no. 11, pp. 2322-2330, 2008.

[5] R. K. Aaron and D. M. Ciombor, "Acceleration of experimental endochondral ossification by biophysical stimulation of the progenitor cell pool," Journal of Orthopaedic Research, vol. 14, no. 4, pp. 582-589, 1996.

[6] T. Kitaori, H. Ito, E. M. Schwarz et al., "Stromal cell-derived factor 1/CXCR4 signaling is critical for the recruitment of mesenchymal stem cells to the fracture site during skeletal repair in a mouse model," Arthritis and Rheumatism, vol. 60, no. 3, pp. 813-823, 2009.

[7] Z. Schwartz, B. J. Simon, M. A. Duran, G. Barabino, R. Chaudhri, and B. D. Boyan, "Pulsed electromagnetic fields enhance BMP-2 dependent osteoblastic differentiation of human mesenchymal stem cells," Journal of Orthopaedic Research, vol. 26, no. 9, pp. 1250-1255, 2008.

[8] M. T. Tsai, W. J. Li, R. S. Tuan, and W. H. Chang, "Modulation of osteogenesis in human mesenchymal stem cells by specific pulsed electromagnetic field stimulation," Journal of Orthopaedic Research, vol. 27, no. 9, pp. 1169-1174, 2009.

[9] L. Y. Sun, D. K. Hsieh, T. C. Yu et al., "Effect of pulsed electromagnetic field on the proliferation and differentiation potential of human bone marrow mesenchymal stem cells," Bioelectromagnetics, vol. 30, no. 4, pp. 251-260, 2009.

[10] C. T. Brighton, W. Wang, R. Seldes, G. Zhang, and S. R. Pollack, "Signal transduction in electrically stimulated bone cells," Journal of Bone and Joint Surgery A, vol. 83, no. 10, pp. 1514-1523, 2001.

[11] W. H. S. Chang, L. T. Chen, J. S. Sun, and F. H. Lin, "Effect of pulse-burst electromagnetic field stimulation on osteoblast cell activities," Bioelectromagnetics, vol. 25, no. 6, pp. 457-465, 2004.

[12] M. De Mattei, A. Caruso, G. C. Traina, F. Pezzetti, T. Baroni, and V. Sollazzo, "Correlation between pulsed electromagnetic fields exposure time and cell proliferation increase in human osteosarcoma cell lines and human normal osteoblast cells in vitro," Bioelectromagnetics, vol. 20, no. 3, pp. 177-182, 1999.

[13] P. Diniz, K. Soejima, and G. Ito, "Nitric oxide mediates the effects of pulsed electromagnetic field stimulation on the osteoblast proliferation and differentiation," Nitric Oxide, vol. 7, no. 1, pp. 18-23, 2002.

[14] R. A. Luben, C. D. Cain, and M. C. Y. Chen, "Effects of electromagnetic stimuli on bone and bone cells in vitro: inhibition of responses to parathyroid hormone by low-energy low-frequency fields," Proceedings of the National Academy of Sciences of the United States of America, vol. 79, no. 13, pp. 41804184, 1982.

[15] K. Nie and A. Henderson, "MAP kinase activation in cells exposed to a $60 \mathrm{~Hz}$ electromagnetic field," Journal of Cellular Biochemistry, vol. 90, no. 6, pp. 1197-1206, 2003.

[16] R. J. Fitzsimmons, J. T. Ryaby, S. Mohan, F. P. Magee, and D. J. Baylink, "Combined magnetic fields increase insulinlike growth factor-II in TE-85 human osteosarcoma bone cell cultures," Endocrinology, vol. 136, no. 7, pp. 3100-3106, 1995.

[17] P. Diniz, K. Shomura, K. Soejima, and G. Ito, "Effects of pulsed electromagnetic field (ELF-PEMF) stimulation on bone tissue like formation are dependent on the maturation stages of the osteoblasts," Bioelectromagnetics, vol. 23, no. 5, pp. 398-405, 2002.

[18] C. F. Martino, D. Belchenko, V. Ferguson, S. Nielsen-Preiss, and H. J. Qi, "The effects of pulsed electromagnetic fields on the cellular activity of SaOS-2 cells," Bioelectromagnetics, vol. 29, no. 2, pp. 125-132, 2008.

[19] H. P. Wiesmann, M. Hartig, U. Stratmann, U. Meyer, and U. Joos, "Electrical stimulation influences mineral formation of osteoblast-like cells in vitro," Biochimica et Biophysica Acta, vol. 1538, no. 1, pp. 28-37, 2001.

[20] P. Diniz, K. Shomura, K. Soejima, and G. Ito, "Effects of pulsed electromagnetic field (ELF-PEMF) stimulation on bone tissue like formation are dependent on the maturation stages of the osteoblasts," Bioelectromagnetics, vol. 23, no. 5, pp. 398-405, 2002.

[21] K. L. R. Grace, W. J. Revell, and M. Brookes, “The effects of pulsed electromagnetism on fresh fracture healing: osteochondral repair in the rat femoral groove," Orthopedics, vol. 21, no. 3, pp. 297-302, 1998.

[22] K. E. Hammerick, A. W. James, Z. Huang, F. B. Prinz, and M. T. Longaker, "Pulsed direct current electric fields enhance osteogenesis in adipose-derived stromal cells," Tissue Engineering A, vol. 16, no. 3, pp. 917-931, 2010.

[23] N. Selvamurugan, S. Kwok, A. Vasilov, S. C. Jefcoat, and N. C. Partridge, "Effects of BMP-2 and pulsed electromagnetic field (ELF-PEMF) on rat primary osteoblastic cell proliferation and gene expression," Journal of Orthopaedic Research, vol. 25, no. 9, pp. 1213-1220, 2007.

[24] Z. Schwartz, B. J. Simon, M. A. Duran, G. Barabino, R. Chaudhri, and B. D. Boyan, "Pulsed electromagnetic fields enhance BMP-2 dependent osteoblastic differentiation of human mesenchymal stem cells," Journal of Orthopaedic Research, vol. 26, no. 9, pp. 1250-1255, 2008.

[25] C. Grassi, M. D’Ascenzo, A. Torsello et al., "Effects of $50 \mathrm{~Hz}$ electromagnetic fields on voltage-gated $\mathrm{Ca} 2+$ channels and their role in modulation of neuroendocrine cell proliferation and death," Cell Calcium, vol. 35, no. 4, pp. 307-315, 2004.

[26] R. Piacentini, C. Ripoli, D. Mezzogori, G. B. Azzena, and C. Grassi, "Extremely low-freauency electromagnetic fields promote in vitro neurogenesis via upregulation of Cavl-channel activity," Journal of Cellular Physiology, vol. 215, no. 1, pp. 129139, 2008.

[27] F. Bersani, F. Marinelli, A. Ognibene et al., "Intramembrane protein distribution in cell cultures is affected by $50 \mathrm{~Hz}$ pulsed magnetic fields," Bioelectromagnetics, vol. 18, no. 7, pp. 463-469, 1997.

[28] S. Tofani, D. Barone, M. Cintorino et al., "Static and ELF magnetic fields induce tumor growth inhibition and apoptosis," Bioelectromagnetics, vol. 22, no. 6, pp. 419-428, 2001.

[29] R. Iorio, S. Delle Monache, F. Bennato et al., "Involvement of mitochondrial activity in mediating ELF-EMF stimulatory effect on human sperm motility," Bioelectromagnetics, vol. 32, no. 1, pp. 15-27, 2011.

[30] M. Simkó, "Cell type specific redox status is responsible for diverse electromagnetic field effects," Current Medicinal Chemistry, vol. 14, no. 10, pp. 1141-1152, 2007.

[31] S. M. Tanaka, J. Li, R. L. Duncan, H. Yokota, D. B. Burr, and C. H. Turner, "Effects of broad frequency vibration on cultured osteoblasts," Journal of Biomechanics, vol. 36, no. 1, pp. 73-80, 2003. 
[32] C. M. Yang, C. S. Chien, C. C. Yao, L. D. Hsiao, Y. C. Huang, and C. B. Wu, "Mechanical strain induces collagenase-3 (MMP-13) expression in MC3T3-E1 osteoblastic cells," Journal of Biological Chemistry, vol. 279, no. 21, pp. 22158-22165, 2004.

[33] J. H. Jansen, H. Jahr, J. A. N. Verhaar et al., "Stretchinduced modulation of matrix metalloproteinases in mineralizing osteoblasts via extracellular signal-regulated kinase-1/2," Journal of Orthopaedic Research, vol. 24, no. 7, pp. 1480-1488, 2006.

[34] D. C. Williams, G. B. Boder, and R. E. Toomey, "Mineralization and metabolic response in serially passaged adult rat bone cells," Calcified Tissue International, vol. 30, no. 3, pp. 233-246, 1980.

[35] C. L. M. Bauréus Koch, M. Sommarin, B. R. R. Persson, L. G. Salford, and J. L. Eberhardt, "Interaction between weak low frequency magnetic fields and cell membranes," Bioelectromagnetics, vol. 24, no. 6, pp. 395-402, 2003.

[36] W. Y. Cheung, "Calmodulin plays a pivotal role in cellular regulation,” Science, vol. 207, no. 4426, pp. 19-27, 1980.

[37] R. K. Aaron, B. D. Boyan, D. M. Ciombor, Z. Schwartz, and B. J. Simon, "Stimulation of growth factor synthesis by electric and electromagnetic fields," Clinical Orthopaedics and Related Research, no. 419, pp. 30-37, 2004.

[38] F. Bersani, F. Marinelli, A. Ognibene et al., "Intramembrane protein distribution in cell cultures is affected by $50 \mathrm{~Hz}$ pulsed magnetic fields," Bioelectromagnetics, vol. 18, no. 7, pp. 463-469, 1997.

[39] A. Chiabrera, B. Bianco, E. Moggia, and J. J. Kaufman, "ZeemanStark modeling of the RF EMF interaction with ligand binding," Bioelectromagnetics, vol. 21, no. 4, pp. 312-324, 2000.

[40] O. Massot, B. Grimaldi, J. M. Bailly et al., "Magnetic field desensitizes 5-HT1B receptor in brain: pharmacological and functional studies," Brain Research, vol. 858, no. 1, pp. 143-150, 2000.

[41] M. D. Kottke, E. Delva, and A. P. Kowalczyk, "The desmosome: cell science lessons from human diseases," Journal of Cell Science, vol. 119, no. 5, pp. 797-806, 2006.

[42] A. M. Khalil and W. Qassem, "Cytogenetic effects of pulsing electromagnetic field on human lymphocytes in vitro: chromosome aberrations, sister-chromatid exchanges and cell kinetics," Mutation Research, vol. 247, no. 1, pp. 141-146, 1991.

[43] J. Schimmelpfeng and H. Dertinger, "The action of $50 \mathrm{~Hz}$ magnetic and electric fields upon cell proliferation and cyclic AMP content of cultured mammalian cells," Bioelectrochemistry and Bioenergetics C, vol. 30, pp. 143-150, 1993.

[44] A. H. Parola, N. Porat, and L. A. Kiesow, "Chicken embryo fibroblasts exposed to weak, time-varying magnetic fields share cell proliferation, adenosine deaminase activity, and membrane characteristics of transformed cells," Bioelectromagnetics, vol. 14, no. 3, pp. 215-228, 1993.

[45] J. Walleczek and T. F. Budinger, "Pulsed magnetic field effects on calcium signaling in lymphocytes: dependence on cell status and field intensity," FEBS Letters, vol. 314, no. 3, pp. 351-355, 1992.

[46] J. Schimmelpfeng, J. C. Stein, and H. Dertinger, "Action of $50 \mathrm{~Hz}$ magnetic fields on cyclic AMP and intercellular communication in monolayers and spheroids of mammalian cells," Bioelectromagnetics, vol. 16, no. 6, pp. 381-386, 1995.

[47] R. Markoll, D. M. Da Silva Ferreira, and T. K. Toohil, "Pulsed signal therapy for the treatment of musculoskeletal conditions: a millennium paradigm," APLAR Journal of Rheumatology, vol. 7, no. 3, pp. 292-305, 2004.
[48] E. Finkelstein, W. Chang, P. H. G. Chao et al., "Roles of microtubules, cell polarity and adhesion in electric-field-mediated motility of 3T3 fibroblasts," Journal of Cell Science, vol. 117, no. 8, pp. 1533-1545, 2004.

[49] X. Li and J. Kolega, "Effects of direct current electric fields on cell migration and actin filament distribution in bovine vascular endothelial cells," Journal of Vascular Research, vol. 39, no. 5, pp. 391-404, 2002.

[50] B. Katz and R. Miledi, "The statistical nature of the acetycholine potential and its molecular components," Journal of Physiology, vol. 224, no. 3, pp. 665-699, 1972.

[51] C. L. M. Bauréus Koch, M. Sommarin, B. R. R. Persson, L. G. Salford, and J. L. Eberhardt, "Interaction between weak low frequency magnetic fields and cell membranes," Bioelectromagnetics, vol. 24, no. 6, pp. 395-402, 2003.

[52] R. Ohata, N. Tomita, and Y. Ikada, "Effect of a static magnetic field on ion transport in a cellulose membrane," Journal of Colloid and Interface Science, vol. 270, no. 2, pp. 413-416, 2004.

[53] R. A. Rogachefsky, R. D. Altman, M. S. Markov, and H. S. Cheung, "Use of a permanent magnetic field to inhibit the development of canine osteoarthritis," Bioelectromagnetics, vol. 25, no. 4, pp. 260-270, 2004.

[54] E. K. Onuma and S. W. Hui, "Electric field-directed cell shape changes, displacement, and cytoskeletal reorganization are calcium dependent," Journal of Cell Biology, vol. 106, no. 6, pp. 2067-2075, 1988.

[55] E. M. Goodman, B. Greenebaum, and M. T. Marron, "Effects of electromagnetic fields on molecules and cells," International Review of Cytology, vol. 158, pp. 279-338, 1995.

[56] R. Goodman, J. Bumann, L. X. Wei, and A. S. Henderson, "Exposure of human cells to electromagnetic fields: effect of time and field strength on transcript levels," Electromagnetic Biology and Medicine, vol. 11, no. 1, pp. 19-28, 1992.

[57] M. R. Cook, C. Graham, H. D. Cohen, and M. M. Gerkovich, "A replication study of human exposure to $60-\mathrm{Hz}$ fields: effects on neurobehavioral measures," Bioelectromagnetics, vol. 13, no. 4, pp. 261-285, 1992.

[58] J. Kim, K. S. Choi, Y. Kim et al., "Bioactive effects of graphene oxide cell culture substratum on structure and function of human adipose-derived stem cells," Journal of Biomedical Materials Research $A$.

[59] J. Kim, Y. R. Kim, Y. Kim et al., "Graphene-incorporated chitosan substrata for adhesion and differentiation of human mesenchymal stem cells," Journal of Materials Chemistry B, vol. 1, no. 7, pp. 933-938, 2013.

[60] J. Kim, D. H. Kim, K. T. Lim et al., "Charged nanomatrices as efficient platforms for modulating cell adhesion and shape," Tissue Engineering C, vol. 18, no. 12, pp. 913-923, 2012.

[61] K. T. Lim, C. S. Cho, Y. H. Choung et al., "Influence of static magnetic field stimulation on cells for tissue engineering," Tissue Engineering and Regenerative Medicine, vol. 6, no. 1, pp. 250-258, 2009. 


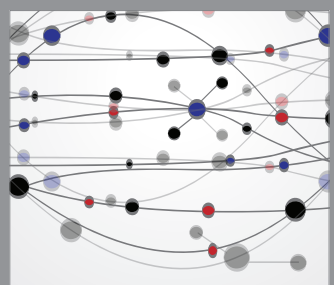

The Scientific World Journal
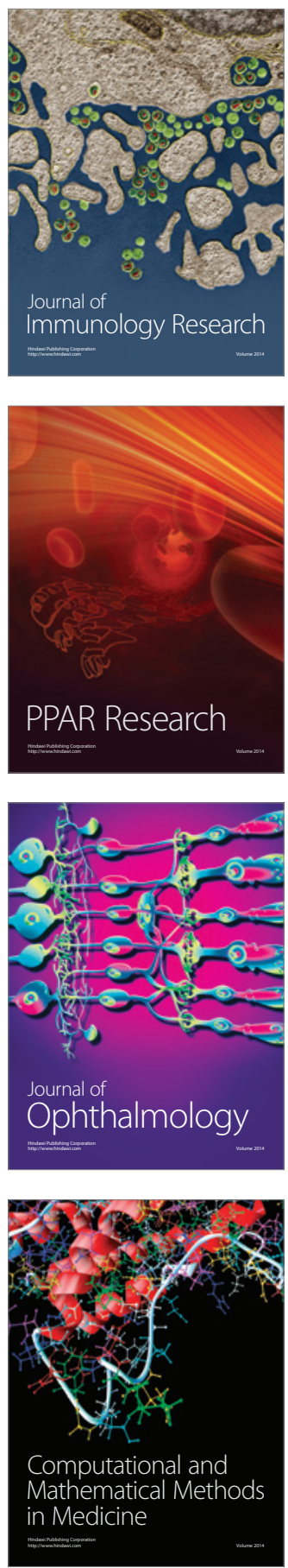

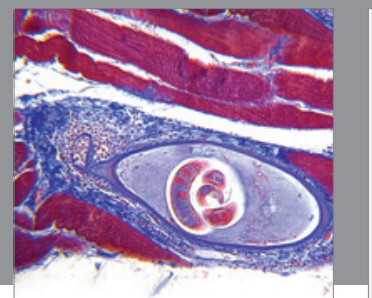

Gastroenterology

Research and Practice
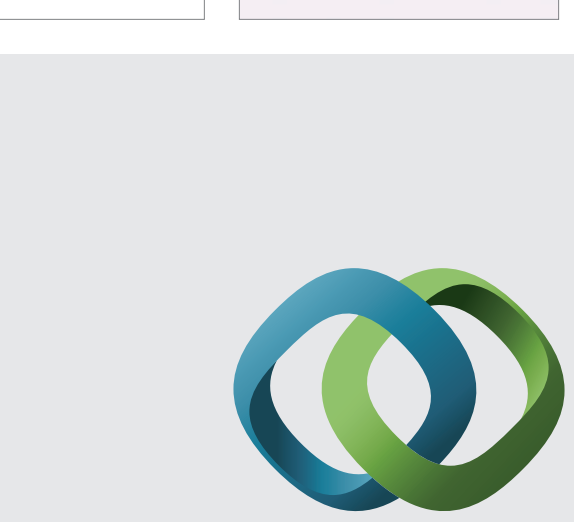

\section{Hindawi}

Submit your manuscripts at

http://www.hindawi.com
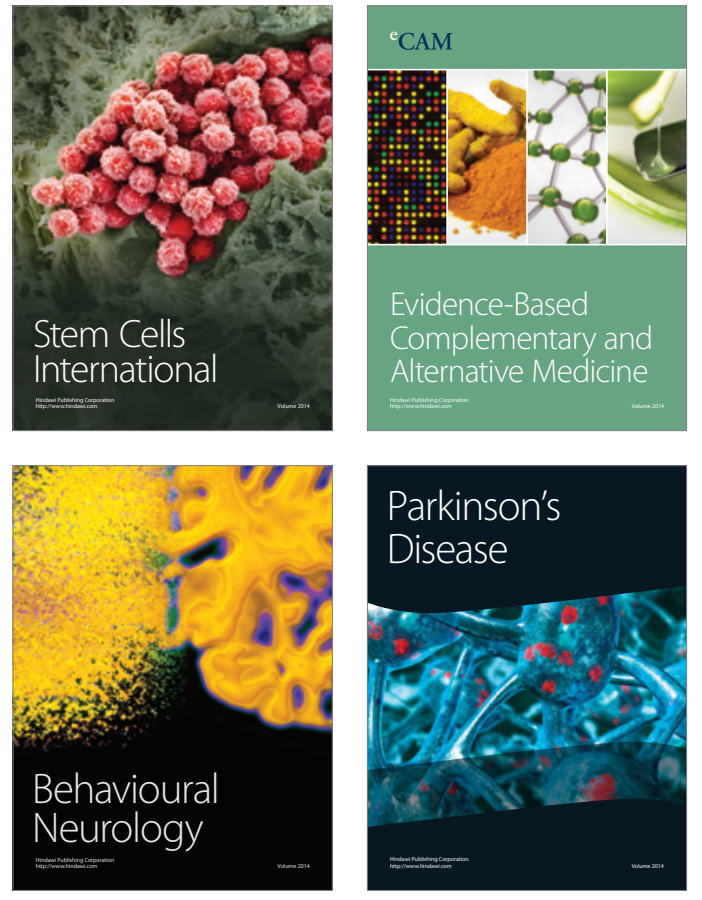
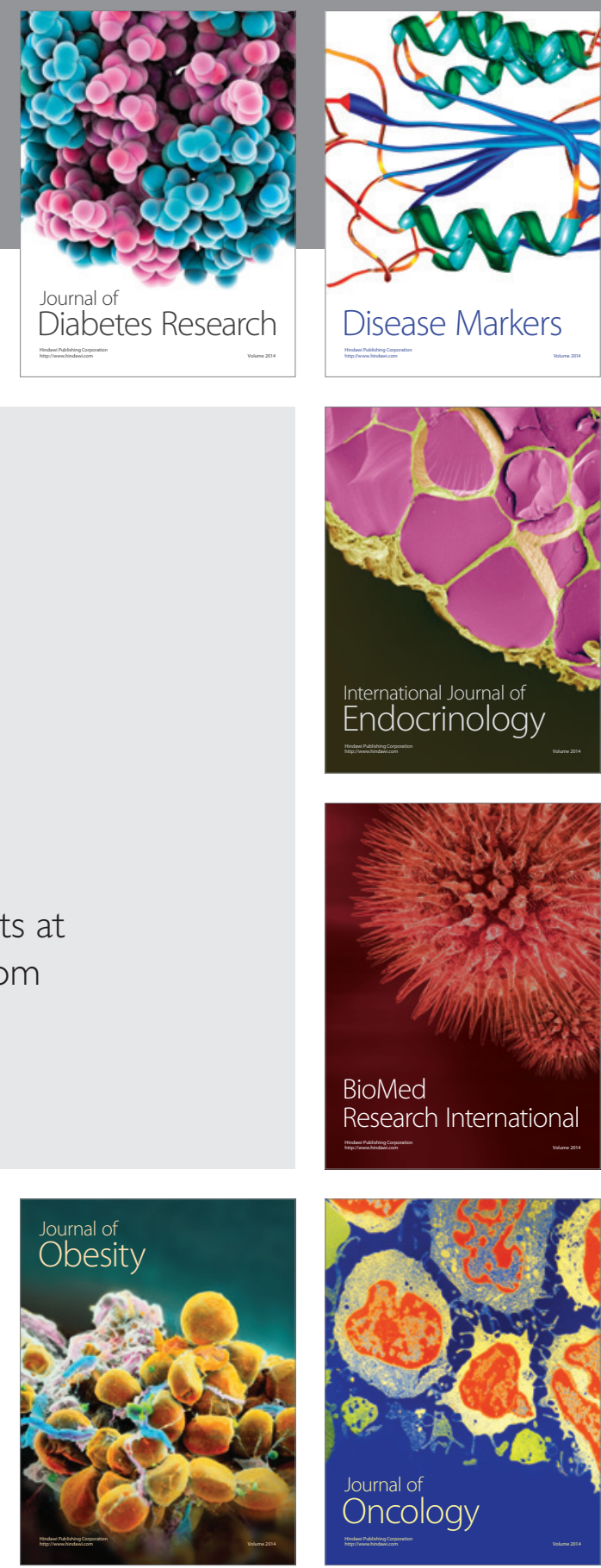

Disease Markers
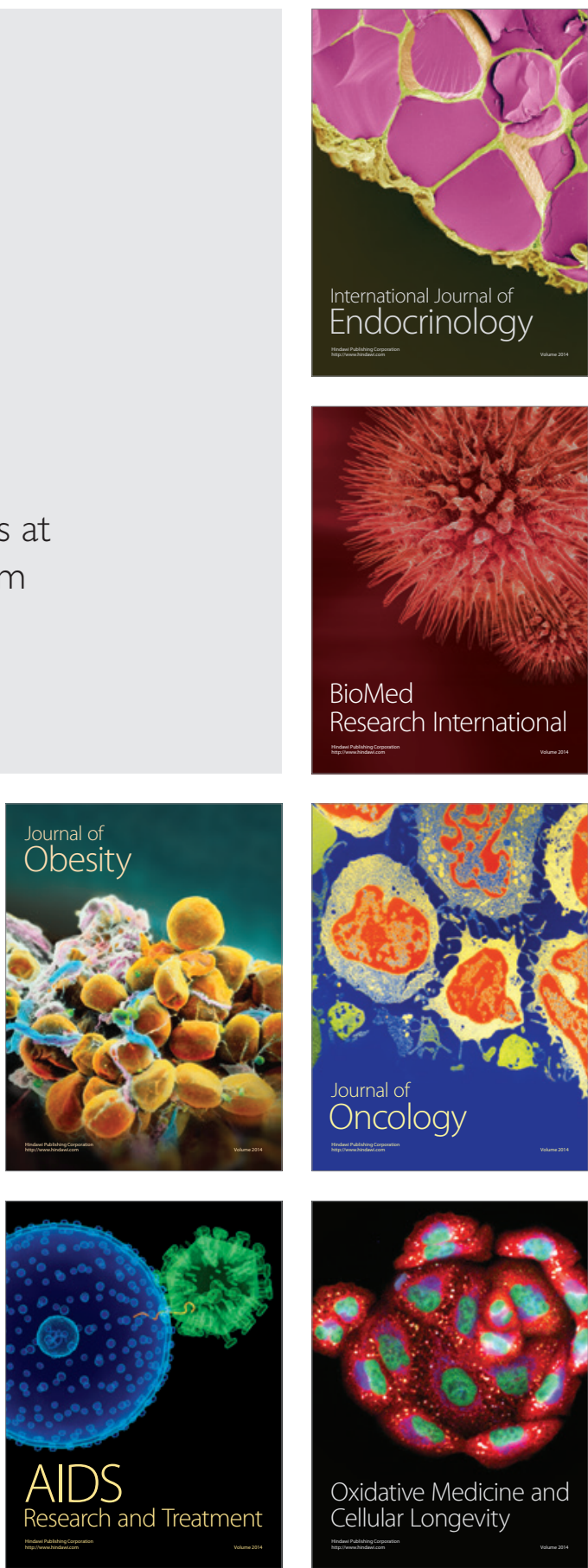